\title{
دراسة تجريبية للوصول لأفضل هعامل جودة لوصلات أقمشة الجينز
}

\author{
إعداد \\ د/ أملر عبد السميح \\ مدرس الملابس والنسيج بقسم الاقتصاد المنزلي \\ كلية التربية النوعية - جامعة المنصورة
}

مجلة بحوث التربية النوعية ـ جامعة المنصورة

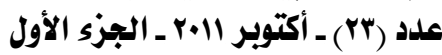




\title{
دراسة تجريبية للوصول لأهضل هماهل جودة لوصلات أقمشة البينزز
}

\author{
إعداد \\ * دأمل عبد السميع
}

\section{:}

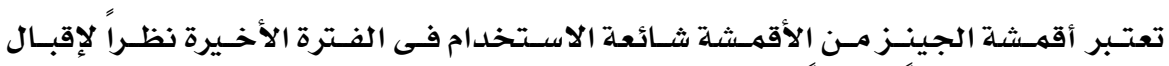

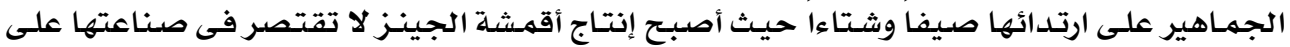

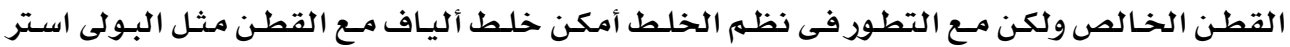

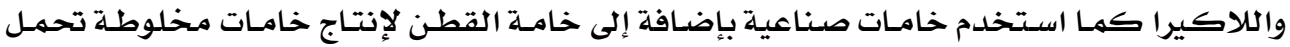

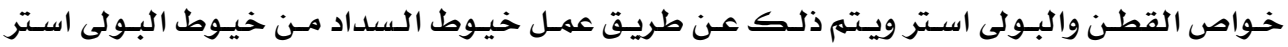

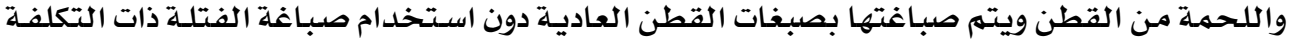

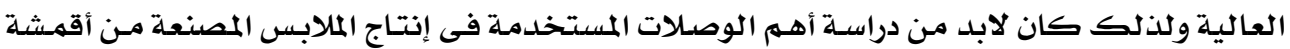

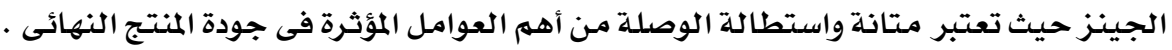




\title{
دراسة تجريبية للوصول لأفضل معاهل جودة لوصلات أقمشة الجينز
}

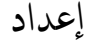 \\ * دأمل عبد السميع
}

الاقدمهة :

تعتبر الملابس المصنوعة مـن أقمشة الجينز أكثر الملابس انتشارا وتحتل المرتبـة الأولى بـين

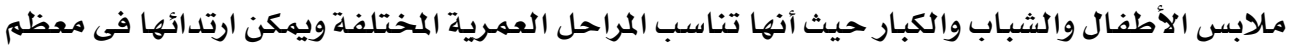

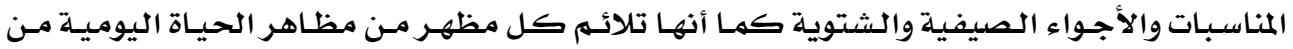

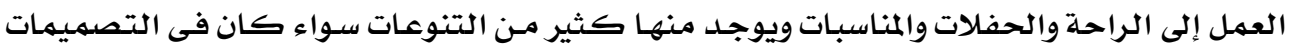

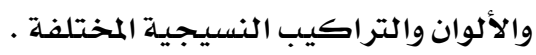

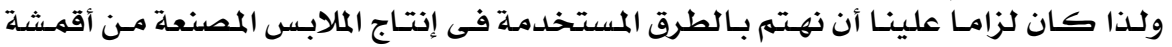

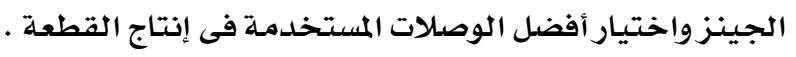

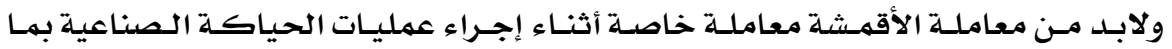

$$
\text { يتناسب وطبيعة الخامسة وكذذك الغرض المنتج من أجله (17 ) . }
$$

تعرف الحياكة بأنها عملية تهدف إلى تثبيت أو وصل طبقـة واحسدة أو جـزء منهـا مـع قهـاث

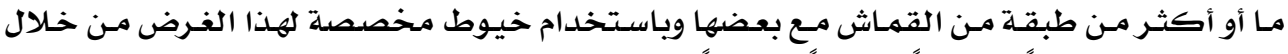

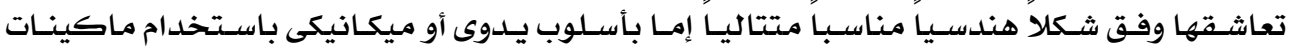

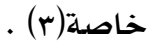

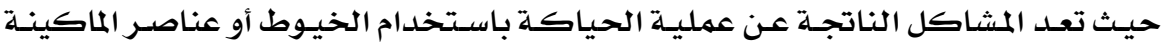

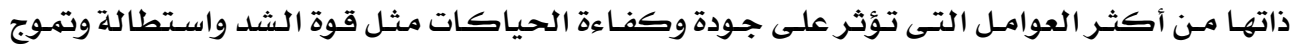

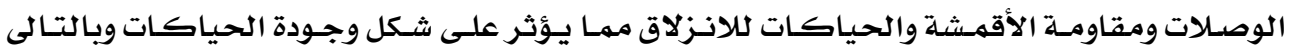

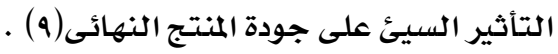

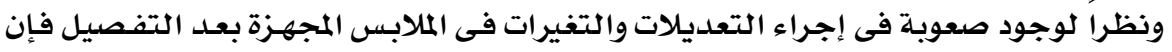

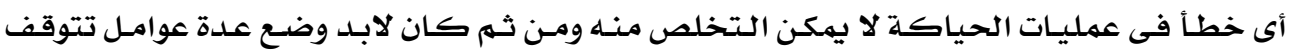
عليها جودة الحياكة وهى : الحيل

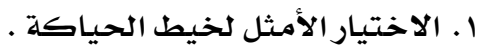

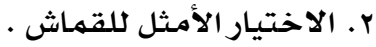

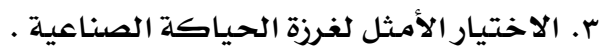

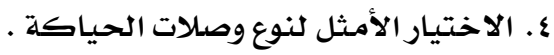

* مدرس الملابس والنسيج بقسهم الاقتصاد المنزلي - كلية التربية النوعية - جامعة المنصورة 
مجلة بحوث التربية النوعية - عدد بr - أكتوبر ll r - الجزء الؤول لـ

$$
\begin{aligned}
& \text { ه. الاختيار الأمثل لشكل الموديل . }
\end{aligned}
$$

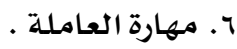

$$
\begin{aligned}
& \text { V. الماكينة . ل ملارها }
\end{aligned}
$$

والحياكة الجيدة هى الحياكة التى لها القدرة على تحمل الاحتكاك والشد الواقع عليها

أن تكون آمنـلة ضد الغسيل .

فكل هـذه العوامـل تسـاير على تحقيـق كفـاءة الحيـاكـة وجـودة المنتـج النهـائى بـدون عيـوب

تقلل من قيمـة(r) ) .

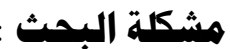

تواجـه صـنـاع الملابسس الجـاهزة المصنعـة مـن أقمسشة الجينـز صعوبـات ومسشاكل عديـدة أثنـاء مـرحلـة تشغيل الجينـزوذلك بسـبـب انفـراد أقهـشة الجينـز بـبعض الخـواص الطبيعيـة مثل الصـلابـة الزائدة والسمك أثناء الحياكة وكذلك أنواع الماكينات المختلفة المستخدمة في حياكة الأقمشة الجنزيـة ، وأيضاً فى نوع الوصلات المستخدمهة فى المنتج الملبسىى .

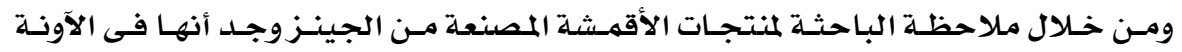

الأخيرة أصسبـحت تستخلدم وصسلات ذات جـودة غـير عاليـة مهـا يـؤثر على العمـر الاسـتهلاكى للهنـتج

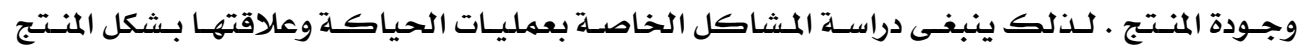
وتحسـين خواصسه الطبيعيـة والميكانيكيـة وكـذلك الغـرض مـن المنـتج النهـائى حيـث تكثر المشاكل

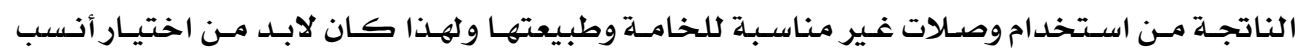

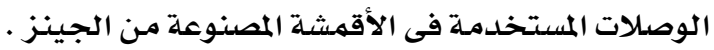

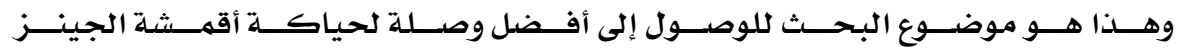

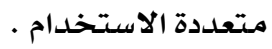

$$
\text { ترجـع أهميـة هذا البـحث إلى : }
$$

ا. تهيئسة أنسـب الظـروف للحسصول على حيـاكـات تتناسـب مـع الخـواص الميكانيكيـة والطبيعيـة

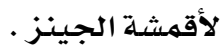

r . تطويـ البححث العلمى لتقديه حلول علميـة للوصول إلى مستوى جودة عالى لوصلات الجينز •

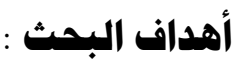

إيجاد علاقة بين نوع الوصلة المستخدمة وكفاءة الاستخدام النهائى . • دراسة تأثير كالا من متانة واستطالة الوصللة على كفاءة الوصلة . إيجاد معامل الجودة للعينات المختبرة . 
1. توجد علاقة ذات دلالة إحصائية بين متانة الوصلة المحاكة وجودة الوصلة .

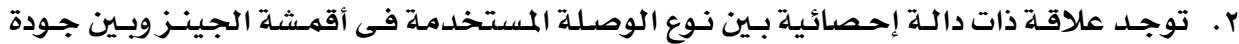

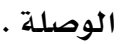

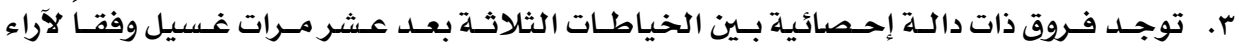
المحكمين . توجن

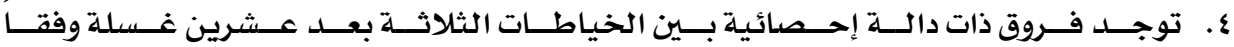

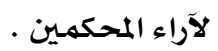

هدود البمث :

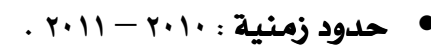

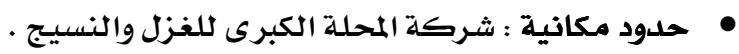

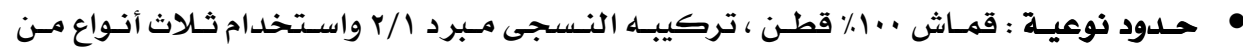

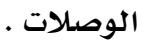

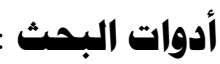

تصميم استمارة استبيان والمعالجة الإحصائية . هنهج البمث :

المنهج الوصفى التجريبى التحليلى لتحقيق أهداف البحث .

الإطار النظرى للبحث :

الخواص الطبيعية والميكانيكية لأقمشة الجينز :

$$
\text { التركيب النسجى : من أكثر التراكيب النسيجية هو المبرد . }
$$

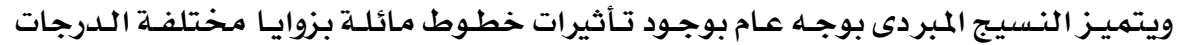

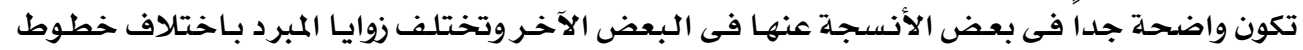
السداء واللحمة . تواضحة أهم خصائص أقمشة الجينز :

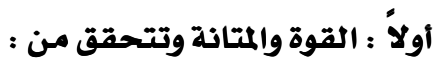

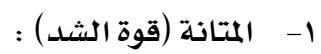

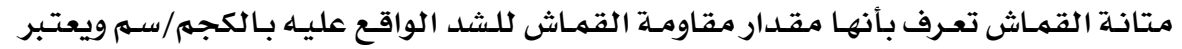

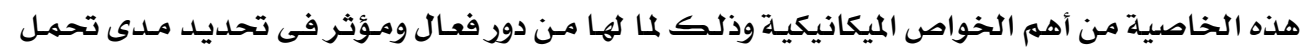

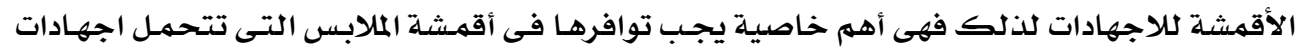




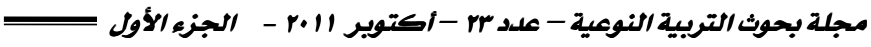

عالية مثل ملابس الجينز وتتوقف قوة الشد على أنواع الشعيرات المكونة لخيوط الأقمشة حيث أن قوة

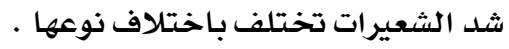
ومن العوامل التى تؤثر على قوة شد الأقمشة :

$$
\begin{aligned}
& \text { 1. قوة الشد الخيط . }
\end{aligned}
$$

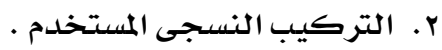

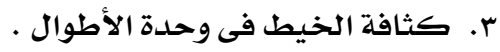

الاستطالة :

تعـرف الاستطالة بأنها مقـدار الزيـادة فى الطـول عنـد التعـرض للشد حتى القطـع ويعتبر

القطن ضعيف نسبياً للاستطالة .

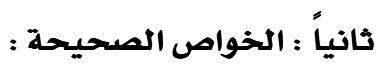

هذه الخاصية يجب توافرها فى جميـع أنواع أقمشـة الملابس وملابس الجينـز تعطى الراحسة

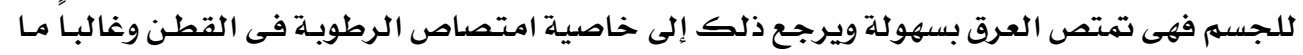

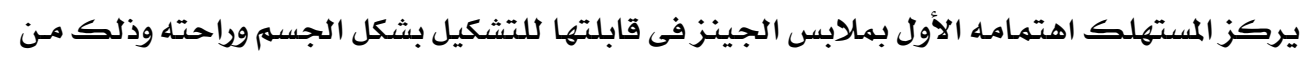

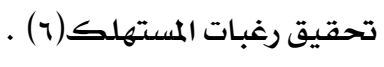

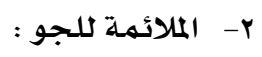

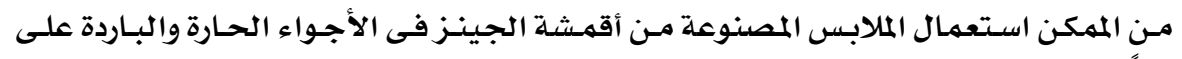

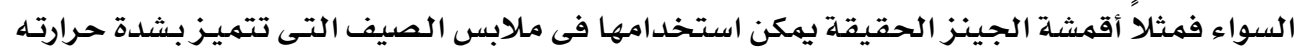

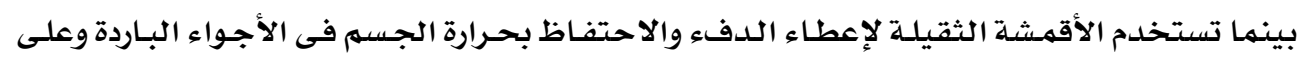

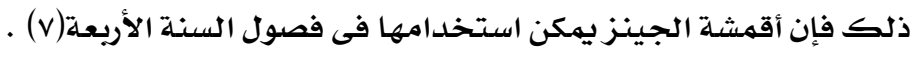

$$
\text { r- باذية الهواء }
$$

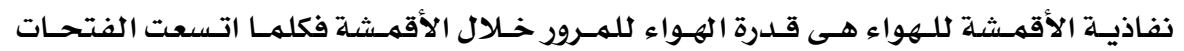

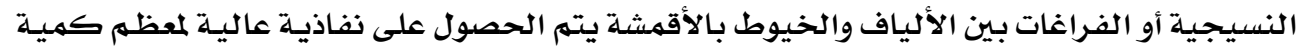

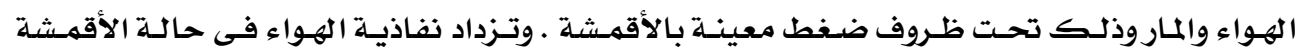

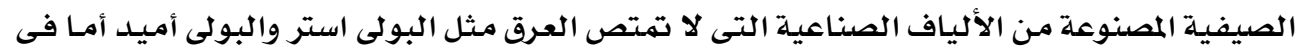

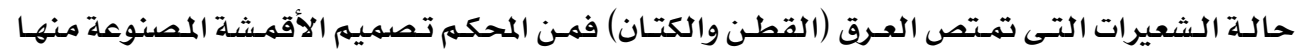

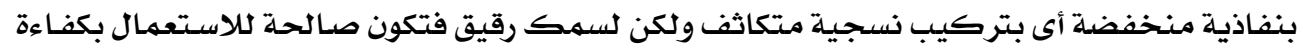

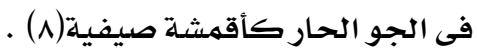

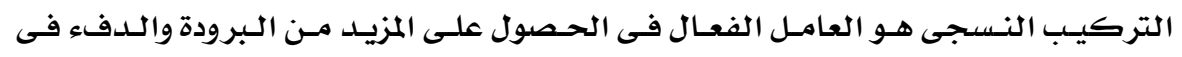

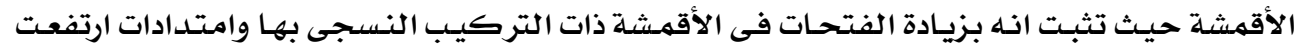

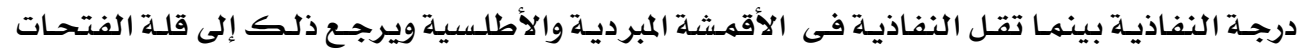

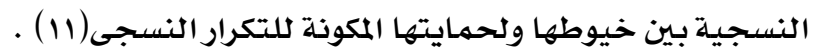


هى عبارة عن عدد من غرز الحياكة متصلة بعضها البعض تعمل على وصل قطعتين قماش

$$
\text { وتسمى بخط الحياكة أو وصلة الحياكة( IV) . }
$$

\section{ويمكن تقسيم الصعوبات الأكثر شيوعاً أثناء الحياكة إلى :}

ا ـ . صعوبات فى تكوين الغرز (غرز مفوتة - غرز مائلة - غرز غير متزنة - كثافة غرز مختلفة) .

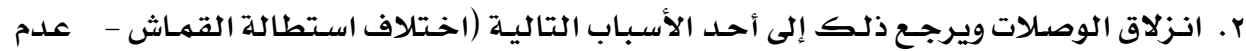

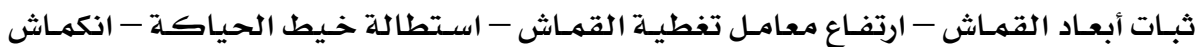

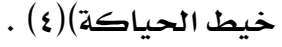

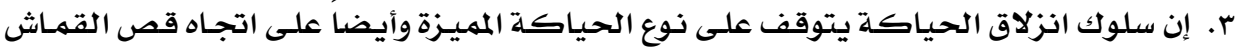

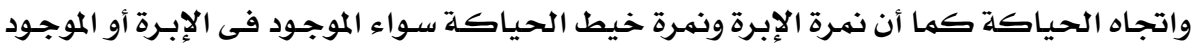

$$
\text { فى المكوك(0) . }
$$

ع. قوة شد عروة الخيط ومعدل الغرز فى وحدة الطول جميعهـا مـتغيرات هامـة تؤثر على قوة شـد

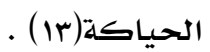

ه. ويـؤثر تركيـب الخامـة أيضـاً على انـزلاق الحياكسة وأيضضاً طريقـة تشطيبها وضـبط تشغيل

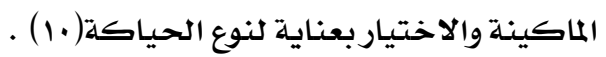

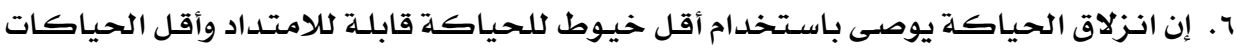

كذلك قابلية للامتداد عند حياكة الأقمشة ذات خاصية الامتداد العالية(ع ا ) .

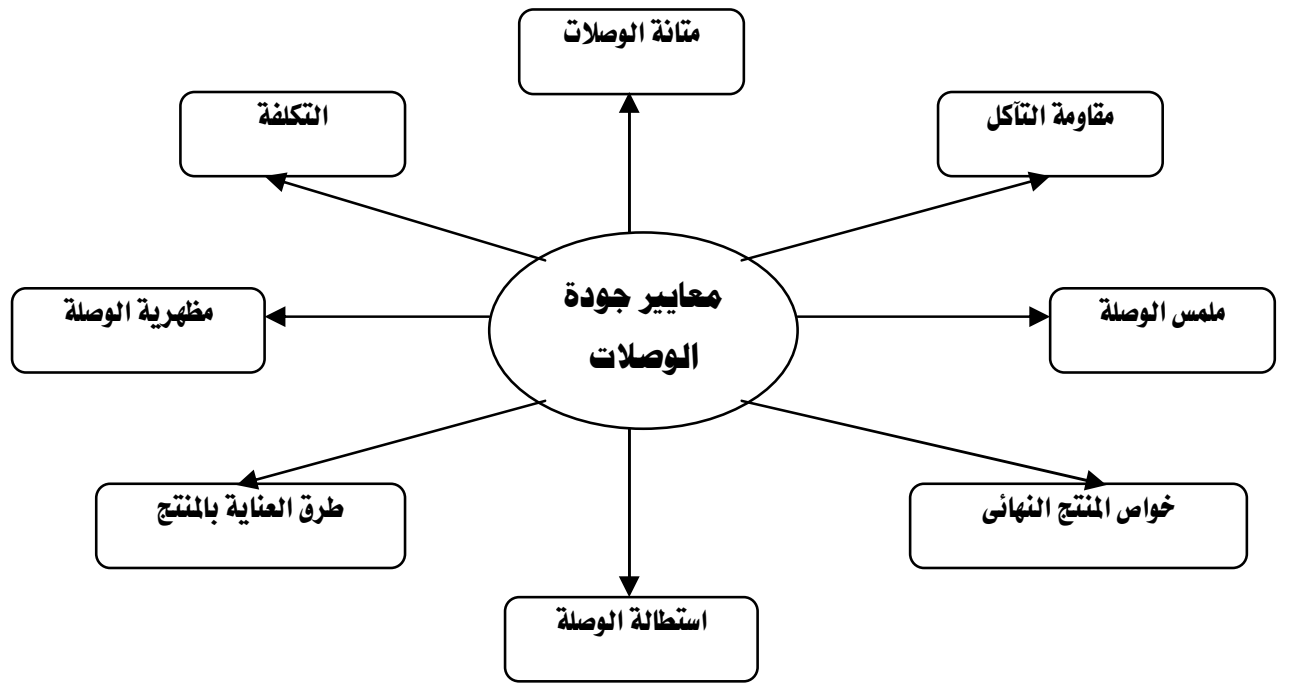

شكل رقم (1) يوضح المعايير المختلفة لجودة الوصلة(10) 
التجارب والاختبارات العماية :

جدول رقم (1) يحدد مواصفات الخامة

\begin{tabular}{|c|c|c|c|c|c|c|c|c|}
\hline \multirow{2}{*}{ التسجي } & \multirow{2}{*}{ الاستطالة } & \multirow{2}{*}{ قوة } & \multirow{2}{*}{ وزن المتر } & \multicolumn{2}{|c|}{ عدد الخيوط فى البوصة } & \multirow{2}{*}{ عرض ع } & \multirow{2}{*}{ اللون } & \multirow{2}{*}{ الخامـــة } \\
\hline & & & & لجحة & سلداs & & & \\
\hline ا & 0,0 & or & rq. & M & rz & ir. & أزرق & قطن.•1\% \\
\hline
\end{tabular}

تصليل الانحدار لدراسة تأثير قوة الشد علي كنفاءة الوصلة :

جدول رقم (r) يوضـح تأثير قوة الشد على كفاءة الوصلة

\begin{tabular}{|c|c|c|c|c|}
\hline الدلالة & قيمة ت & الخطأ في الانحراف المعياري & بيتا & \\
\hline 0.01 & 1.776 & 0.000 & 0.520 & كفاءة الوصلة \\
\hline
\end{tabular}

$\mathrm{R} 2=1.00$

الثابت = 1.036

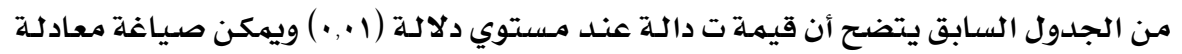
تنبؤيـة لقوة الشد من خلال كفاءة الوصلة علي النحو التالي قوة الشد= 1.036 + 0.520 × كفاءة الوصلية

\section{ارتباط بيرسون بين قوة الشد وكثاءة الوصلة :}

جدول رقم (r) يوضـح الارتباط بين قوة الارتباط وكفاءة الوصلة

\begin{tabular}{|c|c|c|}
\hline الادلالة & كفاءة الوصل & \\
\hline 0.01 & 0.917 & قوة الشد \\
\hline
\end{tabular}

يتضِح من الجدول السـابق وجود ارتبـاط دال موجب بين قوة الشد وكفاءة الوصلية.

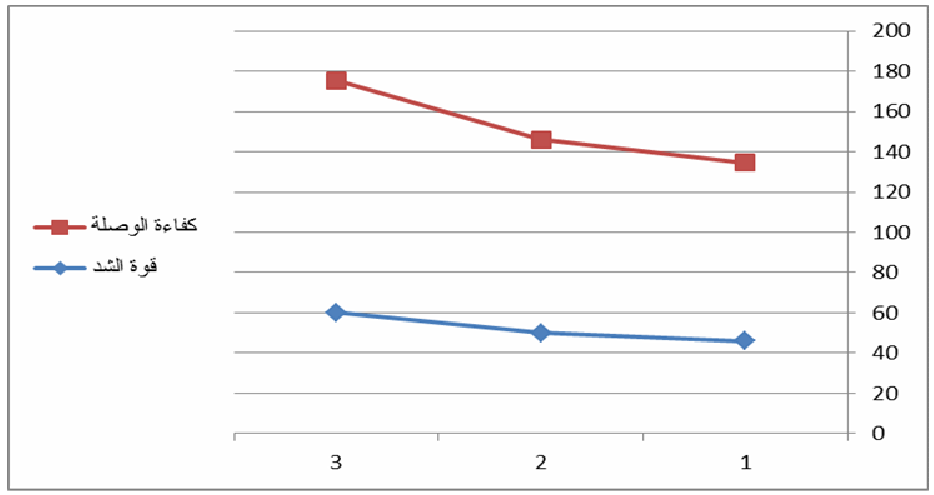

شكل رقم (r) يوضـح كفاءة الوصلة وقوة الشد للوصلات الثلاثة 


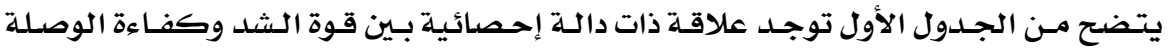

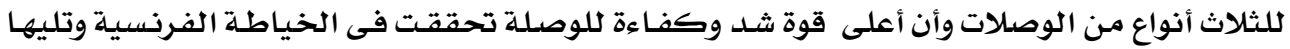

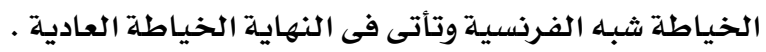

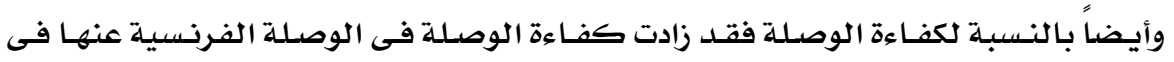

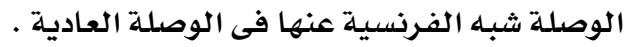

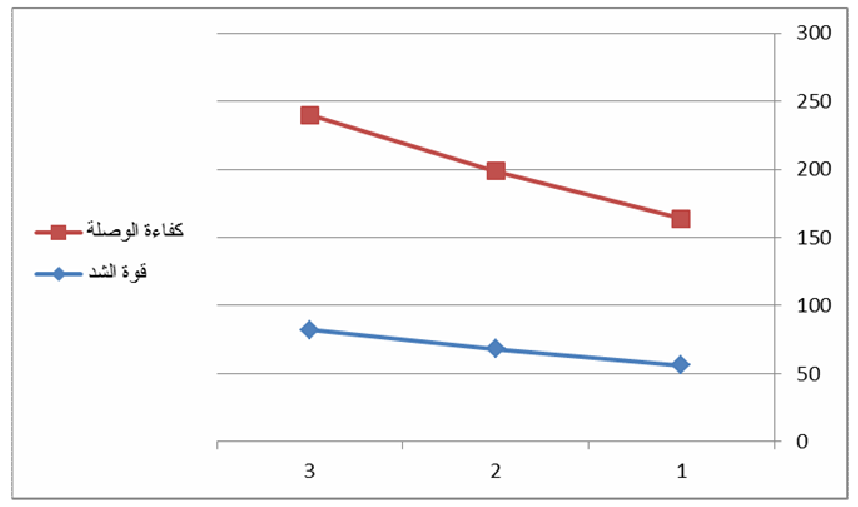

شكل رقم (r) يوضح كفاءة الوصلة وقوة الشد للوصلات الثلاثة بعد · ا غسلات يتضـح فى الجدول أنه توجد علاقة ذات دالة إحصائية بعد تكرار عمليـات الغسيل عشر مـرات بين قوة الشد وكفاءة الوصلة وأن أعلى قوة شد تحققت فى الوصلـلة الفرنسية وتليها شببه الفرنسية

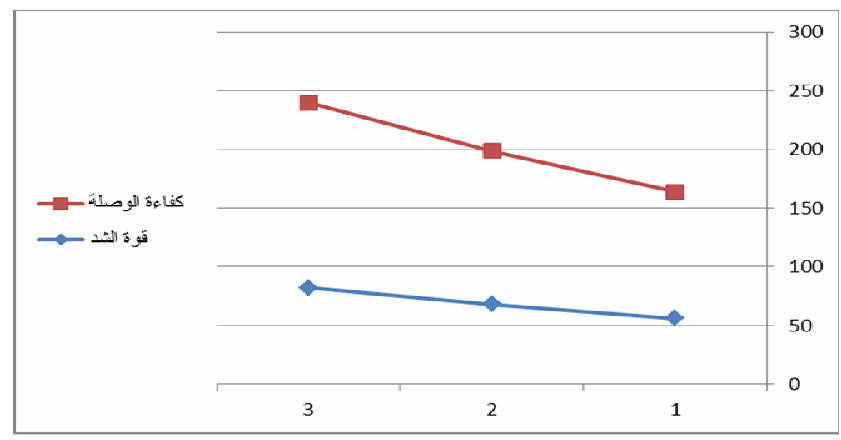

شكل رقم (ع) يوضح كفاءة الوصلة وقوة الشد للوصلات الثلاثة بعد ·r غسلة

يتضح من الجدول أنه توجد علاقة ذات دالة إحصائية بعد تكرار عمليات الغسيل عشرين مرة

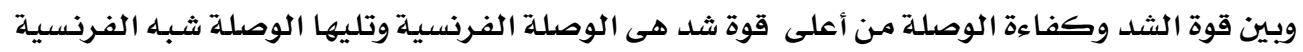

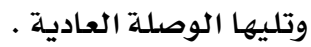


مجلة بحوث التربية النوعية - عدد rr - أكتوبر ll م - الجزء الأول بـ

\begin{tabular}{|c|c|c|c|}
\hline الخياطة الفرنسية & الخياطة شبه الفرنسية & الخياطة العادية & المينة \\
\hline 7 & $\varepsilon$ & $r, 0$ & قطن •.1\% \\
\hline
\end{tabular}

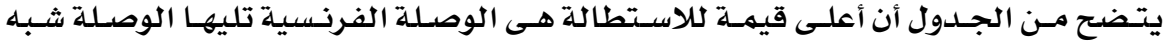
الفرنسية يلها الوصلة العادية .

جدول رقم (ه) يوضتح نتائج اختبارات الاستطالة بعد · ا غسلات

\begin{tabular}{|c|c|c|c|}
\hline الخياطة الفرنسية & الخياطة شبه الفرنسية & الخياطة العادية & العينة \\
\hline 7 & $r, \Lambda$ & $r, r$ & قطن ..1\% \\
\hline
\end{tabular}

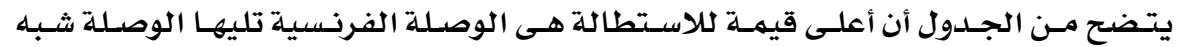

الفرنسيـة يلها الوصلة العادية بعد . 1 غسلات .

جدول رقم (؟) يوضـح نتائج اختبـارات الاستطالة بعد ·r غسلة

\begin{tabular}{|c|c|c|c|}
\hline الخياطة الفرنسية & الخياطة شبه الفرنسية & الخياطة العادية & العينة \\
\hline 0,1 & $r, q$ & $r, r$ & قطن •.1\% \\
\hline
\end{tabular}

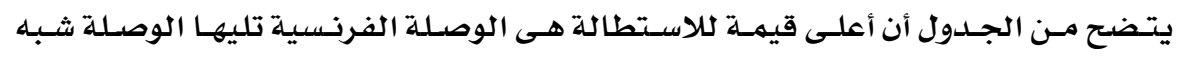

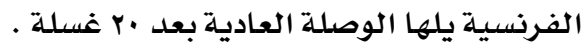

الصدق والثبات

الصدق باستخدام الاتساق الداخلي بين درجة كل عبارة واللدرجة الكلية للاستبيان :

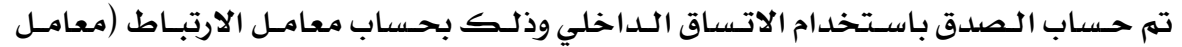
ارتباط بيرسون) بين درجـة كل عبارة والدرجة الكلية للاستبيان، والجدول التالي يوضـح ذلك :

جدول رقم (v) قيم معاملات الارتباط بين درجـة كل عبـارة والدرجـة الكلية للاستبيـان

\begin{tabular}{|c|c|c|c|c|c|}
\hline الدلالة & الارتباط & + & الدلالة & الارتباط & - \\
\hline$\cdot, \cdot 1$ & $\cdot$, YOA & -7 & $\cdot, \cdot 1$ & $\cdot, \Lambda \cdot r$ & -1 \\
\hline$\cdot, \cdot 1$ & - NOr & $-Y$ & $\cdot, \cdot 1$ & $\cdot, \wedge \wedge \wedge$ & $-r$ \\
\hline$\cdot, \cdot 1$ & $\cdot, 9 . r$ & $-\Lambda$ & $\cdot, \cdot 1$ & - , VrA & -r \\
\hline$\cdot, \cdot 1$ & $\cdot, \mathrm{\wedge Al}$ & -9 & $\cdot, \cdot 1$ & . वr६ & 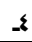 \\
\hline$\cdot, \cdot 1$ & $\cdot$, AYo & -1. & $\cdot, \cdot 1$ & $\cdot, \wedge \leqslant 1$ & - \\
\hline
\end{tabular}

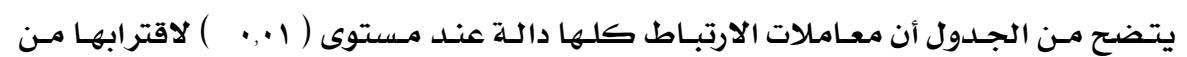

الواحد الصحيح مها يدل على صدق وتجانس عبارات الاستبيان . 


$$
\text { تم حسـاب الثبات عن طريق : معاما }
$$

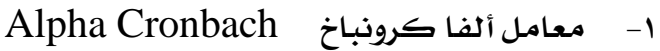

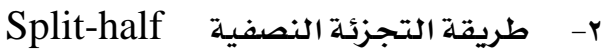

جدول رقم (^) قيم معامل الثبات للاستبيان

\begin{tabular}{||c|c|c|}
\hline ثبات الاستبيان & \\
\hline \hline
\end{tabular}

يتضـح من الجدول السابق أن جميع قيم معاملات الثبات : معامـل الفـا ، التجزئسة النصفية ،

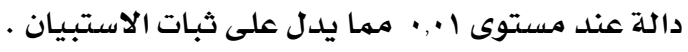

توجد فروق ذات دلالة إحصائية بين الخياطات الثلاث بعد عشر غسلات وفقا لأراء المحكمين . وللتحقق من هذا الفرض تم حساب تحليل التباين لمتوسط درجات الخياطات الثلاث بعـد

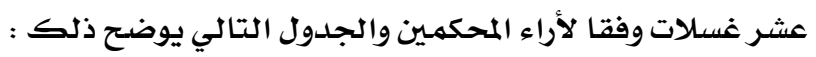

جدول رقم (ه) تحليل التباين لمتوسط درجات الخياطات الثلاث بعد عشر غسلات

\begin{tabular}{|c|c|c|c|c|c|}
\hline الدلالة & قيمة (ف) & درجات الحرية & متوسط المربعات & مجموع المربعات & عشر غسلات \\
\hline \multirow{2}{*}{ ו•,••داJ } & \multirow{2}{*}{ ro,AYq } & $r$ & $M T r, \cdot v r$ & IrrE, IZT & بين المجموعات \\
\hline & & $\{r$ & $1 \Lambda,\{\vee q$ & rvy,IIr & داخل المجموعات \\
\hline & & $\llbracket \varepsilon$ & & Y1..., roY & المجموع \\
\hline
\end{tabular}
وفقا لأراء المحكمين

يتضح من جدول إن قيمة ( ف) كانت (ro,AYq) وهى قيمـة دالة إحصائيا عند مستوى (1 .,. )

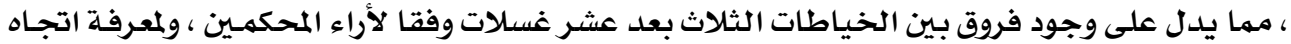

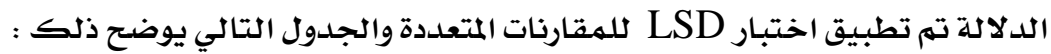

\begin{tabular}{|c|c|c|c|c|c|c|}
\hline الدلالة & قيهة (ت) & الدرجية & العينة الع & الانحراف & الحتوسط & \\
\hline \multirow{2}{*}{ دال عند ا+,• لصالج الخياطة } & \multirow{2}{*}{$11, \cdot 74$} & \multirow{2}{*}{ Iई } & \multirow{2}{*}{10} & $\cdot, \mathrm{r} \cdot \mathrm{O}$ & IT, YO. & الخياطة العادية \\
\hline & & & & $r, \cdot v$ & $r \cdot, \cdot \wedge \cdot$ & الخياطة شبة الفرنسية \\
\hline
\end{tabular}
جدول رقم ( ـ ) الفروق يْ متوسط درجات الخياطة العادية والخياطة شبة الفرنسية 
مجلة بحوث التربية النوعية - عدد rr - أكتوبر ll r - الجزء الؤل لـ

يتضح من الجدول وجود فروق دالة إحصائيا بين الخياطة العادية والخياطة شبة الفرنسية ،

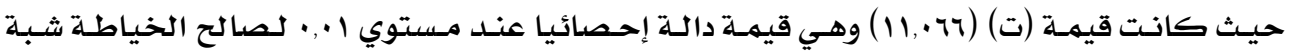

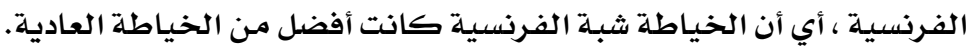

جدول رقم (1) الفروق يْ متوسط درجات الخياطة العادية والخياطة الفرنسية

\begin{tabular}{|c|c|c|c|c|c|c|}
\hline الدلالة & قيمة & الحرية & العينة & الانحراف & الحسوسط المسابي & \\
\hline \multirow{2}{*}{ الخياطة الفرنسية ال, •صالح } & \multirow{2}{*}{$11, \leqslant 7$. } & \multirow{2}{*}{ I\& } & \multirow{2}{*}{10} & $\cdot, v \cdot 0$ & ir, ro. & الخياطة العادية \\
\hline & & & & r, Iro & YA, IAV & الخياطة الفرنسية \\
\hline
\end{tabular}

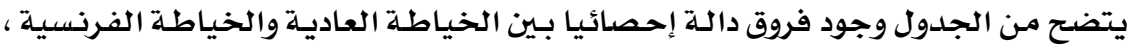

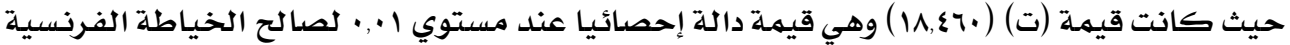

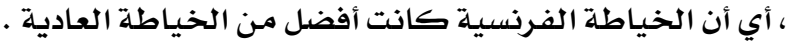

جدول رقم (r ) الفروق يِّ متوسط درجات الخياطة شبـة الفرنسية والخياطة الفرنسية

\begin{tabular}{|c|c|c|c|c|c|c|}
\hline الدلالة & قيمة (ت) & درجات الحرية & العينة & الانعراف المعياري & المتوسط الحسابي & \\
\hline \multirow{2}{*}{ الخياطة الفرنسية الـ • لصالح } & \multirow{2}{*}{$|r, \Sigma 7|$} & \multirow{2}{*}{ iq } & \multirow{2}{*}{10} & $r, \cdot 1 r$ & $r \cdot, \cdot A \cdot$ & الخياطة شبة الفرنسية \\
\hline & & & & r, tro & YA,IAY & الخياطة الفرنسية \\
\hline
\end{tabular}

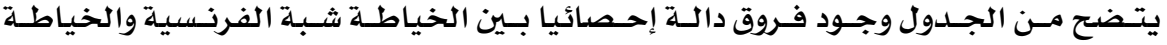

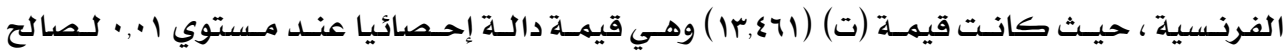

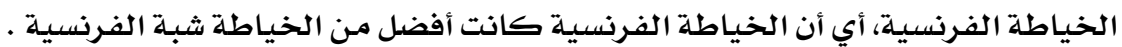

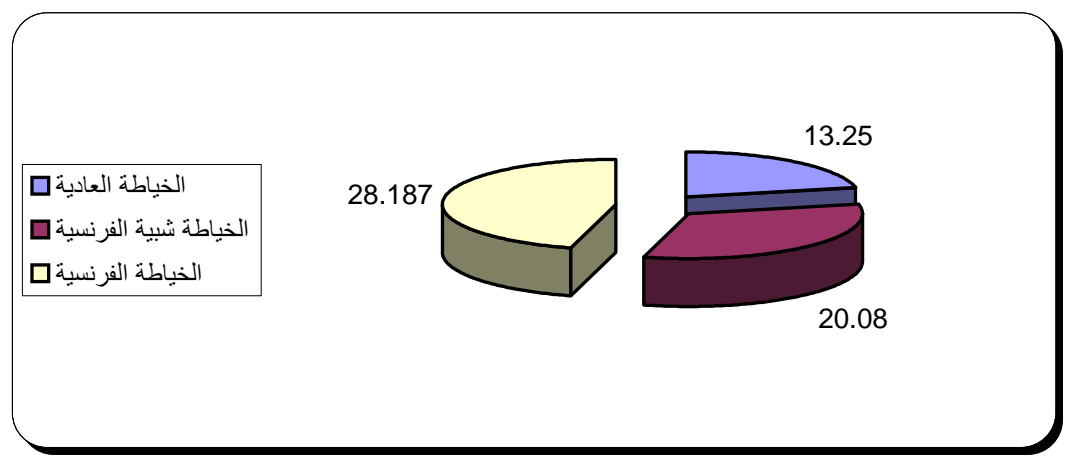

شكل (ه) يوضح الفروق بين الخياطات الثلاث بعد عشر غسلات

الفرض الثاني :

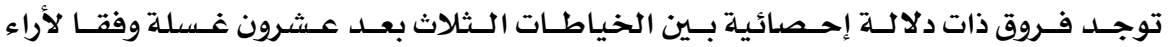
المحكمـين. 
وللتحقق من هـذا الفـرض تم حسـاب تحليـل التبـاين لمتوسط درجـات الخياطـات الثلاث بعـد

عشرون غسلـة وفقا لأراء المحكمـين والجدول التالي يوضسح ذلك :

جدول رقم (r) ) تحليل التباين لمتوسط درجات الخياطات الثلاث بعد عشرون غسلة

وفقا لأراء المحكمين

\begin{tabular}{|c|c|c|c|c|c|}
\hline الدلالة & قيهة (ف) & درجات الحرية & متوسط المربعات & مجموع المربعات & عشرون غسلة \\
\hline \multirow{3}{*}{ 1•,• دال } & \multirow{2}{*}{$r \Lambda, A V Y$} & $r$ & $7 \cdot 1, \mathrm{rr}$. & $M r \cdot r, \Delta \leqslant \cdot$ & بين المجموعات \\
\hline & & $\varepsilon r$ & $r \cdot, \Lambda \leqslant r$ & Aro, rra & داخل المجموعات \\
\hline & & $\xi \xi$ & & $r \cdot V \wedge, q 1 q$ & المجموع \\
\hline
\end{tabular}

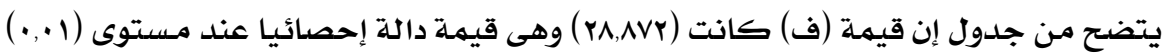
، مما يدل على وجود فروق بين الخياطات الثلاث بعد عشرون غسلـة وفقا لأراء المحكمـين ، ولمعرفة اتجاه

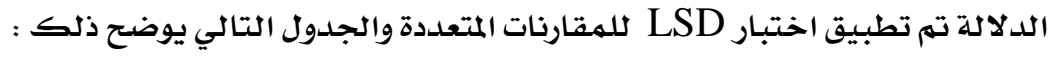
جدول رقم (§ ا ) الفروق يِّ متوسط درجات الخياطة العادية والخياطة شبة الفرنسية

\begin{tabular}{|c|c|c|c|c|c|c|}
\hline الدلالة & قيمة (ت) & درجات الحرية & العينة & الانحراف المعياري & المتوسط الحسابي & \\
\hline \multirow{2}{*}{ الخياطة شبة الفرنسية ال, • لصالح } & \multirow{2}{*}{$11, \cdot 01$} & \multirow{2}{*}{$1 \varepsilon$} & \multirow{2}{*}{10} & $1, v 00$ & 17,094 & الخياطة العادية \\
\hline & & & & ץ,^৭६ & ro, $\cdot 1 r$ & الخياطة شبة الفرنسية \\
\hline
\end{tabular}

يتضح من الجدول وجود فروق دالة إحصائيا بـين الخياطة العادية والخياطة شبـة الفرنسيـة ،

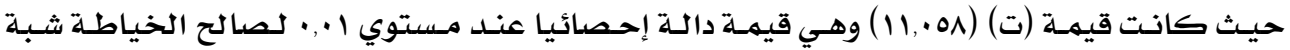
الفرنسية ، أي أن الخياطة شبـة الفرنسية كانت أفضل من الخياطة العادية.

جدول رقم (10) الفروق ِِِ متوسط درجات الخياطة العادية والخياطة الفرنسية

\begin{tabular}{|c|c|c|c|c|c|c|}
\hline الدلالة & قيمة (ت) & درجات الحرية & العينة & الانحراف المعياري & المتوسط الحسابي & \\
\hline \multirow{2}{*}{ الخياطة الفرنسية الب • لصالح } & \multirow{2}{*}{$r \cdot, \cdot r q$} & \multirow{2}{*}{$1 \varepsilon$} & \multirow{2}{*}{10} & $1, Y 00$ & Ir,09r & الخياطة العادية \\
\hline & & & & •, YYY & $r Y, \Sigma 7\rceil$ & الخياطة الفرنسية \\
\hline
\end{tabular}

يتــح مـن الجـــول وجـود فـروق دالـة إحصـائيا بـين الخياطـة العاديـة والخيـاطـة الفرنسيـة ، حيث كانت قيمة (ت) (جس•, •r) وهي قيمـة دالة إحصائيا عند مستوي أ., • لصالح الخياطة الفرنسية ، أي أن الخياطة الفرنسية كانت أفضل من الخياطة العاديـة . جدول رقم (17) الفروق ِِّ متوسط درجات الخياطة شبـة الفرنسية والخياطة الفرنسية

\begin{tabular}{|c|c|c|c|c|c|c|}
\hline الدلالة & قيمة (ت) & درجات الحرية & العينة & الانحراف المعياري & المتوسط الحسابي & \\
\hline \multirow{2}{*}{ الخياطة الفرنسية } & \multirow{2}{*}{ r, rIT } & \multirow{2}{*}{ 18 } & \multirow{2}{*}{10} & ґ,^৭६ & ro, $\cdot 1 r$ & الخياطة شبة الفرنسية \\
\hline & & & & •, VYr & PV, $\$ 7 Y$ & الخياطة الفرنسية \\
\hline
\end{tabular}




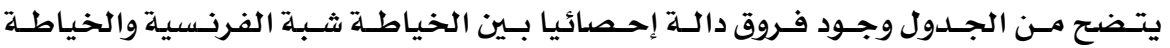

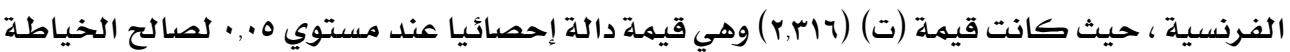

الفرنسية ، أي أن الخياطة الفرنسية كانت أفضل من الخياطة شبـة الفرنسية .

الخياطة شبية الفرنسية الخياطية

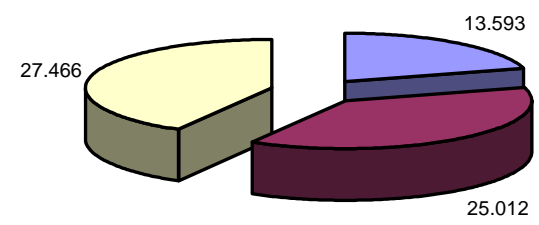

شكل (ج) يوضتح الفروق بين الخياطات الثلاث بعد عشرون غسلة 
جدول بالعرض 
مجلة بحوث التربية النوعية - عدد rr - أكتوبر l|rr - الجزء الؤول

جلدول رقم (^ا ) يوضح معاملات الجودة والمتوسط الوزنى لجميع بنود الاستبيان

\begin{tabular}{|c|c|c|c|}
\hline \multicolumn{3}{|c|}{ الخياطات } & \multirow{2}{*}{+} \\
\hline الخياطة الفرنسية & الخياطة شبة الفرنسية & الخياطة العادية & \\
\hline$\% 1 \cdots$ & $\% 97, \vee$ & $\%$ \%,$\vee$ & -1 \\
\hline$\% 97, v$ & $\% q r, r$ & $\%$ & $-r$ \\
\hline$\%$ & $\%$ & $\% q r, r$ & -r \\
\hline$\% a r, r$ & $\% q r, r$ & $\% 97, \vee$ & $\varepsilon$ \\
\hline$\% 97, \vee$ & $\% a r, r$ & $\%$ & -0 \\
\hline$\%$ & $\%$ & $\% 97,8$ & -7 \\
\hline$\% 97, \vee$ & $\% 97, Y$ & $\% q r, r$ & $-\gamma$ \\
\hline$\% q r, r$ & $\%$ & $\% 9$. & $-\Lambda$ \\
\hline$\%$ & $\% 97, \vee$ & $\%$ & -9 \\
\hline$\% a r, r$ & $\%$. & $\%$ \%,$\vee$ & -1. \\
\hline$\% 9 \vee$ & $\% 90$ & $\%$ \%r, rq & المتوسط العام \\
\hline 1 & r & $r$ & الترتيب \\
\hline
\end{tabular}

الخياطة العهادية

\begin{tabular}{|c|}
\hline البند الاول \\
\hline البند الثاني ـ \\
\hline البند الثالث \\
\hline البند الرابع ه \\
\hline البند الخامس — \\
\hline البند السادس \\
\hline البند السابع \\
\hline البند الثامن \\
\hline البند التاسع ص \\
\hline
\end{tabular}

الخياطة العادية

$86.70 \%$

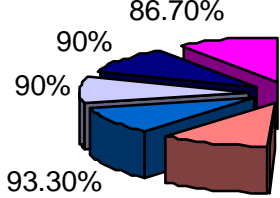

$96.70 \%$
$86.70 \% 90 \%$

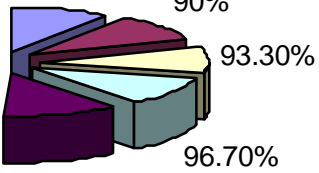

$100 \%$

شكل رقم (v) يوضع معاملات الجودة لجميع بنود تقييم الخياطة العادية

$$
\text { من الشكل السـابق نستخلص مـا يلي : }
$$

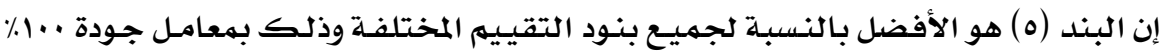

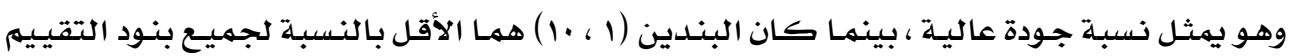

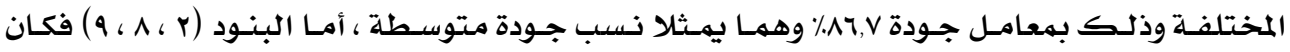

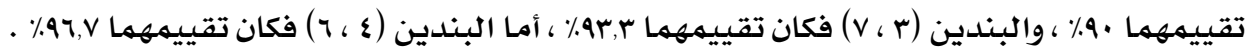




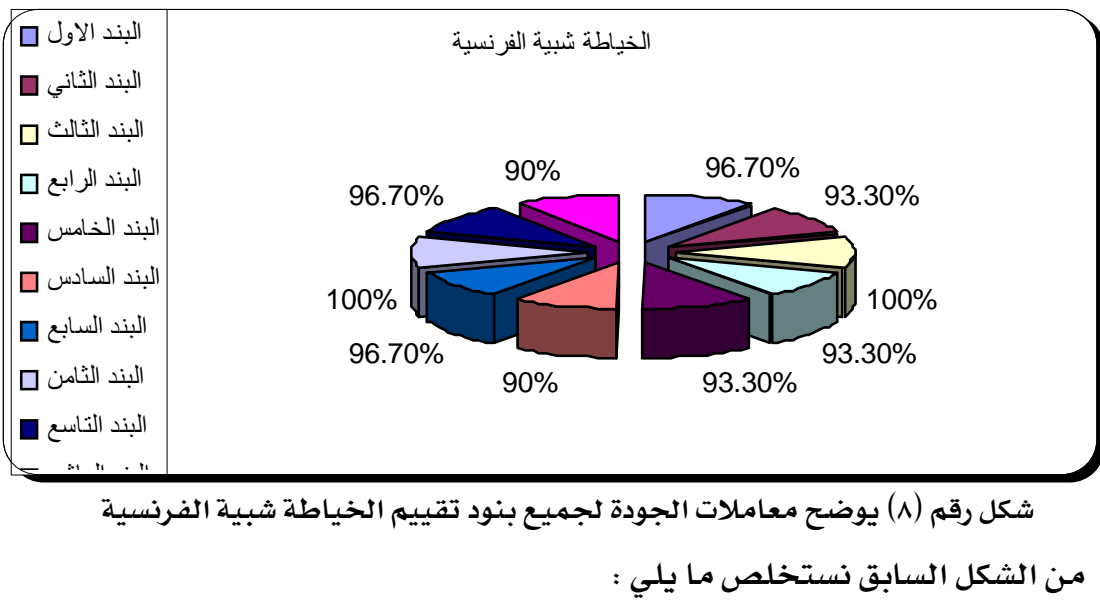

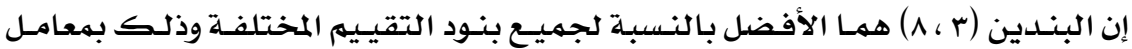

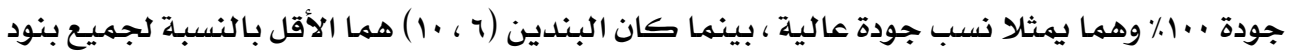

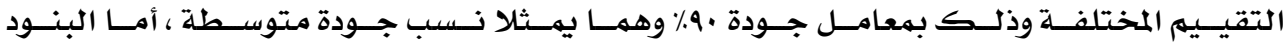

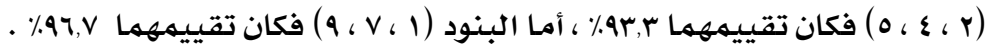

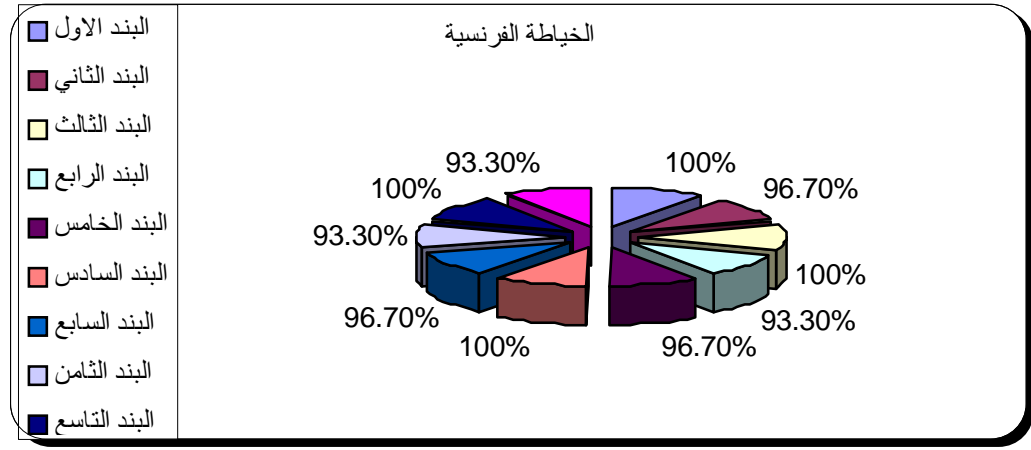

شكل رقم (9) يوضتح معاملات الجودة لجميع بنود تقييم الخياطة الفرنسية

$$
\text { من الشكل السـابق نستخلص ما يلي : }
$$

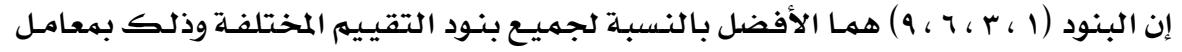

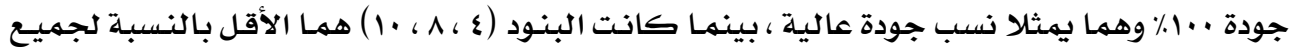

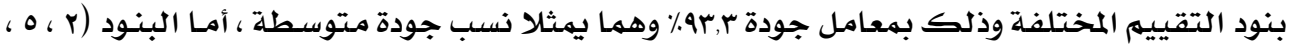

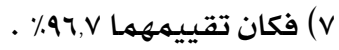



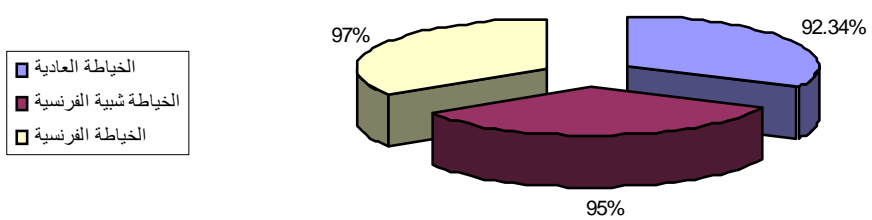

شكل رقم ( ـ ) يوضح التقييم العام لمعامل الجودة للخياطات الثلاث

$$
\text { من الشكل السابق نستخلص ما يلي : }
$$

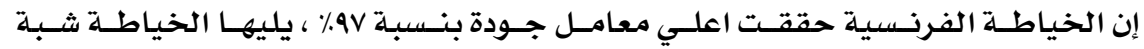

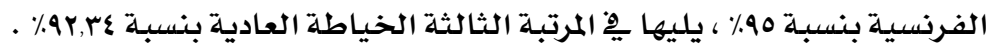

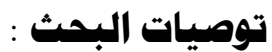

ا ـ التأكيد على الاختيار الأمثل لنوع الوصلة بها يتناسب والمواصفات البنائية للخامـة .

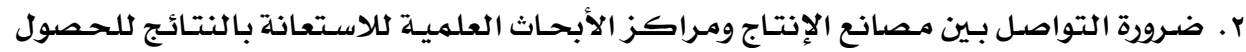

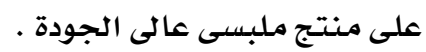




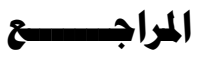

1. الهيئة القومية العامة للتوحيد والقياس قوة الشد والاستطالة وفقاً للمواصفة القياسية هبه/ه ..بم .

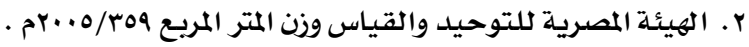

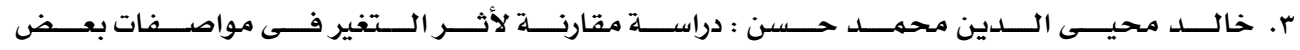

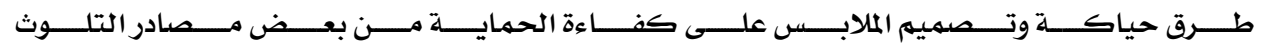

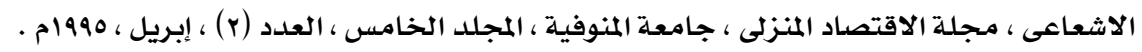

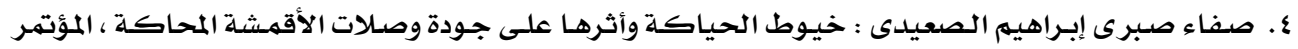

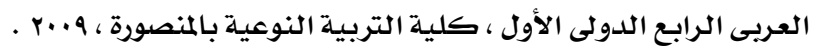

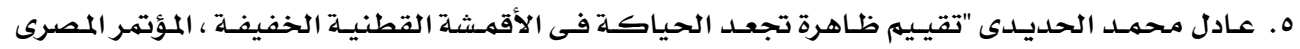
الثالث للاقتصاد المنزلى .

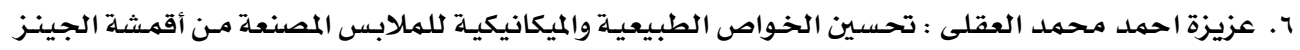

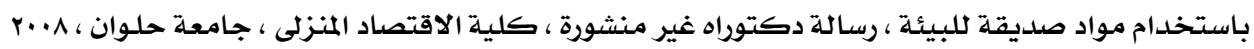

V . . كوثر الزغبى ، أنصار نصر : دراسات فى النسيج ، دار الفكر العربى ، الطبعة الرابعة ، 199V.

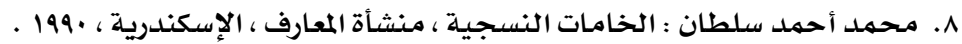

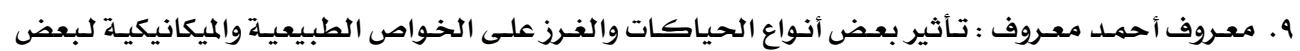

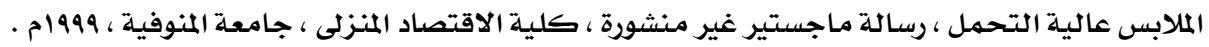

10. Coats "Seam slippage report No. 16 Thread Technology.

11. Denim what is Coming Through, Apparel International, May, 1994.

12. Horold C, Latham, B "The Technology of clothing Manufacture' Second Edition Black Well Science, London, 1996.

13. Hpwarth W. S. "Strength test on sewing thread colothing institute journal Sep. Oct., 1986.

14. Maha Mogamed Malek "Effect of Fabric Geometry and Sewing parameters on seam characteristics Msc. faculty of Engineering Alexandria - University, 1990.

15. No quality product without quality seams focus sewing and www.amann.com.embroidering, 2010.

16. Thamson, A. "The Complete Book of the Swing Machine Berkley Publishers LTD, London, 1980.

17. Wathins, Sosan, Clothing the Portal Environment, Longman, U.S.A., 1976. 